\title{
Correction to: Recurrent Stenoses in Arteriovenous Fistula (AVF) for Dialysis Access: Cutting Balloon Angioplasty Combined with Paclitaxel Drug-Coated Balloon Angioplasty, an Observational Clinical Study (INSTITUTION Trial)
}

\author{
Zehao Tan ${ }^{1}$ • Shaun Xavier Ju Min Chan ${ }^{1} \cdot$ Kun Da Zhuang ${ }^{1}$ - Thijs Urlings ${ }^{2}$ • \\ Sum Leong ${ }^{1} \cdot$ Jasmine Ming Er Chua $^{1} \cdot$ Ankur Patel $^{1} \cdot$ Farah Gillan Irani $^{1}$ • \\ Sivanathan Chandramohan ${ }^{1} \cdot$ Kiang Hiong Tay ${ }^{1} \cdot$ Karthikeyan Damodharan $^{3}$. \\ Richard Hoau Gong Lo ${ }^{1} \cdot$ Nanda Venkatanarasimha ${ }^{1}$ Chow Wei Too ${ }^{1}$. \\ Bien Soo Tan ${ }^{1}$ - Chieh Suai Tan ${ }^{4} \cdot$ Tze Tec Chong ${ }^{5} \cdot$ Hlaing Hlaing Win ${ }^{1}$. \\ Abdul Syafiq Bin Abdul Rahman ${ }^{1}$ Muhammad Syadad Bin Sulaiman ${ }^{1}$. \\ Apoorva Gogna ${ }^{1}$
}

Published online: 15 February 2022

(C) Springer Science+Business Media, LLC, part of Springer Nature and the Cardiovascular and Interventional Radiological Society of Europe (CIRSE) 2022

\section{Correction to:}

Cardiovasc Intervent Radiol

https://doi.org/10.1007/s00270-021-03030-w

The affiliations for two of the authors were mistakenly switched in the initial publication prior to revision on 15 February 2022. The affiliation for the author "Tan Chieh Suai" should be "Department of Renal Medicine" and "Chong Tze Tec" should be "Department of Vascular Surgery".

The original article can be found online at https://doi.org/10.1007/ s00270-021-03030-w.

Zehao Tan

tan.zehao@singhealth.com.sg

1 Department of Vascular and Interventional Radiology, Singapore General Hospital, Singapore, Singapore

2 Department of Radiology, Haaglanden Medical Center, The Hague, The Netherlands

3 Department of Vascular and Interventional Radiology, Madras Institute of Orthopedics and Traumatology (MIOT)

Hospitals, Chennai, India

4 Department of Renal Medicine, Singapore General Hospital, Singapore, Singapore

5 Department of Vascular Surgery, Singapore General Hospital, Singapore, Singapore 